\title{
A six week contextualised physical activity intervention for women living with HIV and AIDS of low socioeconomic status: a pilot study
}

\author{
S. Z. Mabweazara, L. L. Leach, C. Ley and M. Smith
}

\begin{abstract}
Research has consistently shown the benefits of regular physical activity (PA) for women living with HIV and AIDS (WLWHA). This study is a pilot, randomised controlled crossover trial, reporting the effects of a contextualised PA intervention amongst a sample of $21 \mathrm{HIV}$ positive Xhosa-speaking women of low socioeconomic status (SES). The study determined total moderate-to-vigorous PA (TMVPA) as measured subjectively by the Global Physical Activity Questionnaire (GPAQ), total weekly steps (TWS) as measured by a pedometer, and self-efficacy for PA as measured by the Physical Exercise Self-efficacy scale (PESES). Multivariate analysis of covariance (MANCOVA) was used to compute the impact of the intervention on TMVPA, TWS, and self-efficacy for PA from baseline to six weeks, and baseline to 12 weeks post-intervention controlling for pre-test differences in TMVPA. Results showed that participants exposed to the intervention had significant increases in PA as measured by TMVPA ( $\mathrm{p}=.027)$, TWS $(\mathrm{p}=.032)$, as well as exercise self-efficacy $(\mathrm{p}=.000)$ from pre-test to 6 weeks. Insignificant findings were reported for all three variables when measured from baseline to 12 weeks. In conclusion, the findings of the pilot study suggest that the intervention was effective in producing significant increases in PA in a sample of PLWHA of low SES over six weeks. Careful consideration of behavioural constructs, such as self-efficacy, can help WLWHA of low SES to adopt regular PA as a complementary therapy for managing their health.
\end{abstract}

\section{Introduction}

Amongst people living with HIV and AIDS (PLWHA), physical activity (PA) is associated with improvements in mental and physical well-being (Fillipas, Cicuttini, Holland, \& Cherry, 2013; MacArthur, Levine, \& Birk, 1993; Neidig, Smith, \& Brashers, 2003). Aerobic and strength training improve the profile of lymphocytes (O'Brien, Nixon, Glazier, \& Tynan, 2004), body composition, muscle strength and quality of life (Spence, Galantino, Mossberg, \& Zimmerman, 1990).

In Africa, Murenzi (2011) reported that PLWHA, particularly women (Smit et al., 2006), engage in insufficient PA, which may be related to low socioeconomic status (SES) (Economic and Social Research Council, 2014). 
Given the foregoing, the purpose of this study was to evaluate the effect of a six-week pilot PA intervention amongst PLWHA of low SES.

\section{Methods \\ Design}

The study was a crossover trial. Participants were randomly placed in either a 6-week PA intervention or standard care. After a 2 week washout period, participants were crossedover for another 6 weeks. At week 15, the study terminated.

\section{Setting and sample}

The study was conducted at a community centre caring for HIV positive Black African Xhosa-speaking women in a low-income community in the Western Cape Province, SA. Study participants belonged to an HIV support group who consented to participate in the study.

\section{Eligibility/inclusion criteria}

Participants needed to be between 18 and 65 years, HIV positive, as confirmed through medical records, and cleared on the Physical Activity Readiness Questionnaire (PAR-Q). All participants had to be unemployed and not have attained any tertiary education. Additional exclusions were any history of coronary heart disease and/or diabetes, opportunistic infection, pregnancy, and orthopaedic conditions that made PA unsafe.

\section{Protocol}

An information session and information sheets were used to inform participants about the study, and participant written informed consent was obtained. An interviewer-administered questionnaire was used for recording participant demographic information. Height was measured with a stadiometer, and body weight using a calibrated weight scale with participants wearing minimal clothing. Blood pressure was measured, while sitting quietly for approximately $5 \mathrm{~min}$, using a sphygmomanometer. Omron pedometers counted the number of steps per day for seven consecutive days.

Study measurements were total moderate-to-vigorous PA (TMVPA) by the Global Physical Activity Questionnaire (GPAQ) (World health Organisation, 2006), total weekly steps (TWS) by an Omron HJ-720IT-E2 pedometer, self-efficacy for PA using the Physical Exercise Self-efficacy scale (PESES) (Schwarzer \& Renner, 2008), and the stages of motivational readiness for change (SOC) (Marcus \& Simkin, 1993). Two Xhosa-speaking research assistants helped the participants to complete the questionnaires.

The standard care group received nutritional information on healthy eating (Gibney \& Vorster, 2001) designed by a dietician in a once-off 2-hour session. The PA intervention group received logbooks for recording daily PA, and a PA manual with information on home-based exercise activities, the benefits and barriers to PA, and strategies for improving exercise self-efficacy. Figure 1 shows the flow of the study. 


\section{The contextualised physical activity intervention}

The PA intervention was developed in a previous study (Mabweazara, Leach, \& Ley, 2017) and informed by Social Cognitive Theory (SCT) (Bandura, 1986) and the Transtheoretical model (TTM) (Prochaska \& DiClemente, 1983). The PA intervention was delivered in the indigenous Xhosa language, and food packs were used to promote adherence. The intervention employed low-cost activities of daily living (ADLs) using local resources and opportunities.

The PA intervention was two hours each week for six weeks that comprised a combination of educational activities (6o $\mathrm{min}$ ), home-based activities (30 $\mathrm{min}$ ) and a 30-minute group aerobics session. All exercise activities were in line with the American College of Sport Medicine (ACSM) guidelines for individuals infected with HIV (ACSM, 2013).

\section{Ethics statement}

Ethics approval was obtained from the Ethics Committee of the University of the Western Cape (registration number: 14/10/33).

\section{Data analysis}

Descriptive statistics were used to summarise the participants' demographic and clinical characteristics. Levene's test was computed to assess equality of means. Independent t-tests and multivariate analysis of covariance were used to assess differences between groups, and statistical significance was set at an alpha level of $<.05$.

\section{Results}

\section{Sample characteristics}

The mean $( \pm \mathrm{SD})$ age of the participants was 37.57 (8.64) years, height was $1.61(0.06) \mathrm{m}$, weight was $84.52(22.48) \mathrm{kg}$, and BMI was $32.21(7.89) \mathrm{kg} \cdot \mathrm{m}^{-2}$. For education, $4.8 \%$ attended school up to Grade 7; 33\% up to Grade 10; and 61.9\% up to Grade12. The mean $\mathrm{CD} 4{ }^{+}$cell count was $469.68(\mathrm{SD}=157.48)$ cells $/ \mu \mathrm{L}(\mathrm{n}=19)$. Tables 1 and 2 show TMVPA, TWS and self-efficacy at baseline, after six weeks and post-crossover.

Table 1. Total moderate-to-vigorous physical activity, total weekly steps and self-efficacy for physical activity at baseline and after six weeks in the pre-crossover phase. $(n=21)$.

\begin{tabular}{lcc}
\hline Variable & Baseline Mean (SD) & 6 weeks Mean (SD) \\
\hline PA Intervention group $(n=11)$ & \\
TMVPA (min/wk) & $1198.82(872.33)$ & $1530.36(1009.86)$ \\
TWS (steps/wk) & $32198.64(17148.51)$ & $35311.91(17767.08)$ \\
S-E for PA & $10.82(4.31)$ & $16.18(2.18)$ \\
& & \\
Standard care group $(n=10)$ & $1427.50(987.00)$ & $1459.70(954.84)$ \\
TMVPA (min/wk) & $36572.30(11014.70)$ & $38153.86(12081.60)$ \\
TWS (steps/wk) & $14.00(4.08)$ & $14.30(2.45)$ \\
S-E for PA & Note: TMVPA = total & moderate-to-vigorous physical activity; TWS = total \\
weekly steps; S-E for PA = Self-Efficacy for physial activity
\end{tabular}


Table 2. Total moderate-to-vigorous physical activity, total weekly steps and self-efficacy for physical activity at baseline and after six weeks in the post-crossover phase. $(n=21)$.

Variable Baseline Mean (SD) 6 weeks Mean (SD)

PA Intervention group $(n=10)$

$\begin{array}{lc}\text { TMVPA (min/wk) } & 1459.70(954.84) \\ \text { TWS (steps/wk) } & 38153.86(12081.60)\end{array}$

$1750.00(868.29)$

S-E for PA

$14.30(2.45)$

$115006.86(176202.25)$

Standard are group $(n=11)$

TMVPA (min/wk)

$1530.36(1009.86)$

$19.14(0.90)$

TWS (steps/wk)

$35311.91(17767.08)$

$1527.00(1007.00)$

S-E for PA

$16.18(2.18)$

34083.55 (18149.03)

$16.91(2.12)$

Note: TMVPA $=$ total moderate-to-vigorous physical activity; TWS $=$ total weekly steps; S-E for PA = Self-Efficacy for physical activity. 


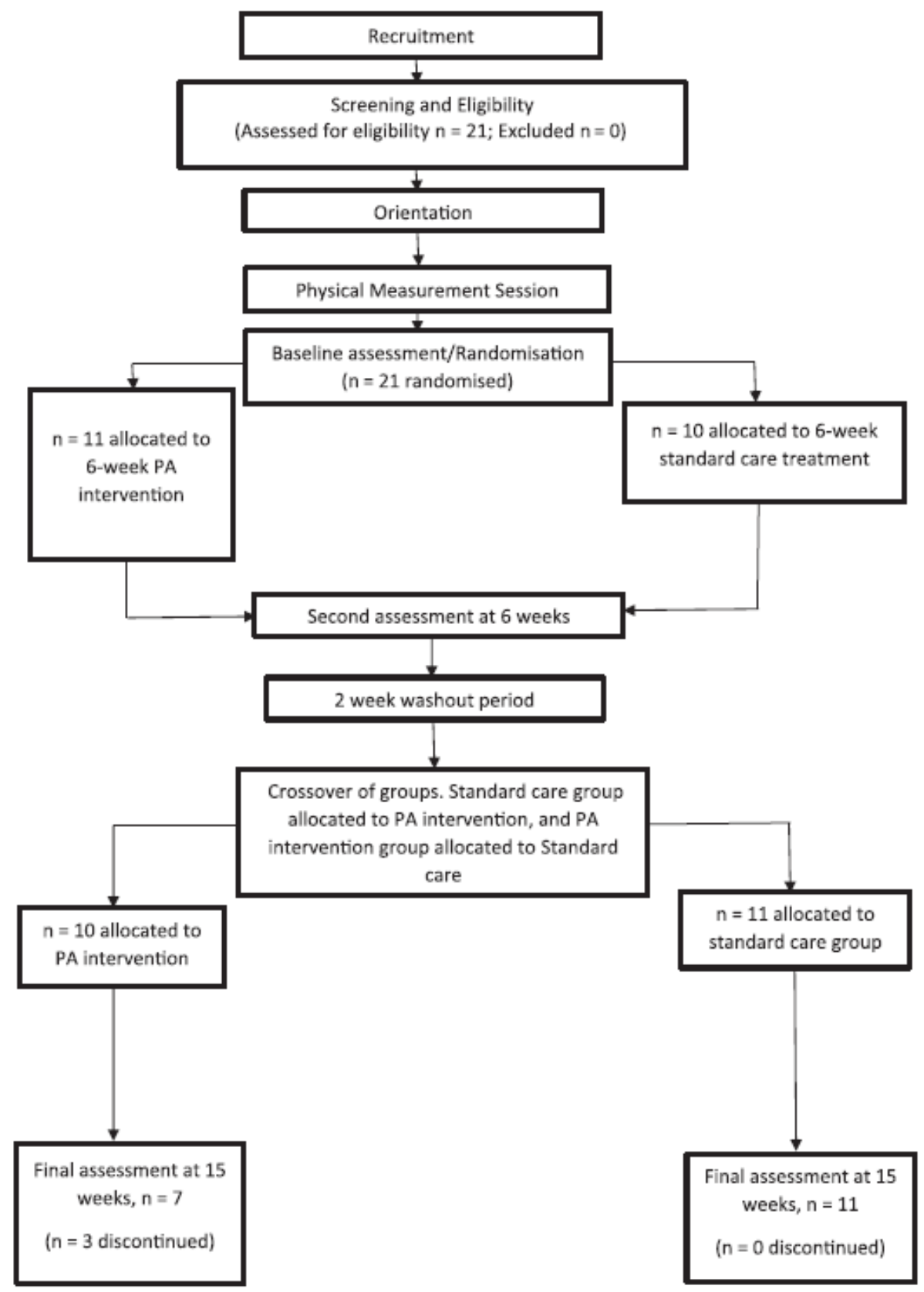

Figure 1. Flow chart of the Randomised controlled cross-over trial.

The results for SOC showed two participants in the precontemplative stage, 11 in the contemplative stage, four in the preparatory stage and one in the action stage.

\section{Baseline assessments}

Levene's tests for TMVPA $(\mathrm{F}=.145, \mathrm{p}=.708)$, TWS $(\mathrm{p}=.612)$ and self-efficacy for PA $(\mathrm{p}=$ .891) were not significant and, thus, equal variances were assumed. Baseline comparison revealed insignificant findings between groups on TWS $(\mathrm{t}=.647, \mathrm{p}=.527)$ and self-efficacy ( $\mathrm{t}$ $=2.167, \mathrm{p}=.05)$, but a significant difference on TMVPA $(\mathrm{t}=.116, \mathrm{p}=.042)$. Thus, preexisting differences on TMVPA were controlled as a covariate. Table 3 indicates that there were significant differences between groups on all three outcome variables (TMVPA: $F=$ 
6.037, $\mathrm{p}=.027$; TWS: $\mathrm{F}=5.586, \mathrm{p}=.032$; self-efficacy: $\mathrm{F}=21.211, \mathrm{p}=.000$ ) from baseline to 6 weeks. Insignificant findings were reported for TMVPA and self-efficacy from baseline to 12 weeks.

\section{Discussion}

The purpose of this study was to evaluate the effects of a six week contextualised intervention aimed at increasing physical activity and self-efficacy for physical activity among HIV positive women of low SES.

Table 3. Multivariate analysis of covariance for PA measures.

\begin{tabular}{|c|c|c|c|c|c|c|}
\hline & $\mathrm{N}$ & $\mathrm{SS}_{\mathrm{b}}$ & df & MS & $\mathrm{F}$ & $p$ \\
\hline \multicolumn{7}{|l|}{ TMVPA } \\
\hline Baseline - 6 weeks & 21 & 408781.158 & 1 & 408781.158 & 6.037 & $.027^{*}$ \\
\hline Baseline - 12 weeks & 18 & 128205.335 & 1 & 128205.335 & .929 & .350 \\
\hline \multicolumn{7}{|l|}{ Total weekly steps } \\
\hline $\begin{array}{l}\text { Baseline }-6 \text { weeks } \\
\text { Self-efficacy for PA }\end{array}$ & 21 & 17912427.740 & 1 & 17912427.740 & 5.586 & $.032^{*}$ \\
\hline Baseline - 6 weeks & 21 & 138.117 & 1 & 138.117 & 21.211 & $<.000^{* *}$ \\
\hline Baseline - 12 weeks & 18 & 192.171 & 1 & 19.217 & 2.243 & .155 \\
\hline
\end{tabular}

Compared to standard care, participants in the physical activity intervention, informed by SCT and TTM, had significant increases in total moderate-to-vigorous physical activity, total weekly steps and self-efficacy for physical activity.

Webel, Moore, Hanson, and Salata (2013) reported that participants increased their physical activity by 300 MET-minutes per week compared to the standard care group. Similar to this study, Webel and colleagues included PA self-monitoring, goal-setting, inclusion of physical activity into activities of daily living, social support and strategies for overcoming barriers to engaging in physical activity, such as the effective use of personal time.

Both studies were also theory-based interventions. Theory-based behaviour change interventions are found to be effective (Sparling, Owen, Lambert, \& Haskell, 2000). Theories assist the researcher to identify the most effective behaviour change techniques (Glanz, Burke, \& Rimer, 2011) and form the base for the development of evidence-based interventions (Sparling et al., 2000). The intervention used in this study applied SCT and TTM. Both theories emphasise the enhancement of self-efficacy (Prochaska \& DiClemente, 1983; Stacey, James, Chapman, Courneya, \& Lubans, 2015). The significant increase in selfefficacy for physical activity could be attributed to the exercises that were chosen and deemed to be enjoyable (Lewis, Williams, Frayeh, \& Marcus, 2016). Including strategies on goal-setting and educating the participants on the benefits and barriers of physical activity are reported to impact positively on health behaviour change (Bandura, 2004).

Focus group discussions were conducted to ascertain the participants' preferred exercise activities. The increases in total moderate-to-vigorous physical activity could be attributed to 
the fact that the intervention included the preferred exercises of the participants. Enjoyment of physical activity has been found to be an important determinant of physical activity initiation (Lewis et al., 2016). Moreover, increased perceived enjoyment of physical activity may result in increased self-efficacy, which may lead to a greater prospect of increasing physical activity behaviour (Lewis et al., 2016).

Good health is a major motivator for engaging in regular physical activity (Tuso, 2015). Educating participants on the health benefits of physical activity, such as walking to church rather than taking a taxi, most likely acted as a positive trigger that reminded them to walk more often (Tuso, 2015). The increase in total weekly steps can be attributed to the fact that participants were conscientised on the health benefits of engaging in regular and appropriate physical activity. Also, educating participants on where to find safe environments to walk very likely assisted them to be more physically active (Tuso, 2015). Persons of low SES are more likely to travel on foot than others (Titheridge, Christie, Mackett, Oviedo Hernandez, \& Ye, 2014). However, Jaggers et al. (2016) conducted a 9-month home-based physical activity intervention among PLWHA and reported no significant differences in steps per day.

\section{Study limitations}

The study sample consisted of a relatively small group. It was a pilot study and statistical power was not calculated at the outset. Furthermore, the intervention period was for six weeks only. The study does not report on the effect of the intervention to mental or physical health of the participants. Further examination of the intervention is still needed before widespread implementation of the intervention.

\section{Conclusion}

The contextualised physical activity intervention resulted in significant increases in total moderate-to-vigorous physical activity, total weekly steps and self-efficacy for physical activity in women living with HIV and AIDS of low SES. Including constructs, such as selfefficacy, participant exercise preferences and social support, can help PLWHA of low SES to adopt regular physical activity, and can serve as adjunct therapy for the management of HIV and AIDS.

\section{Disclosure statement}

No potential conflict of interest was reported by the authors. 


\section{References}

American College of Sports Medicine. (2013). ACSM's guidelines for exercise testing and prescription. Philadelphia: Lippincott Williams \& Wilkins.

Bandura, A. (1986). Social foundations of thought and action: A social cognitive theory. Englewood Cliffs, NJ: Prentice-Hall.

Bandura, A. (2004). Health promotion by social cognitive means. Health Education and Behavior, 31(2), 143-164.

Economic and Social Research Council. (2014). Poorer people are less physically active. Retrieved from http://www.esrc. ac.uk/news-events-andpublications/evidence-briefings/ poorerpeople-are-less-physically-active/

Fillipas, S., Cicuttini, F. M., Holland, A. E., \& Cherry, C. L. (2013). Physical activity participation and cardiovascular fitness in people living with human immunodeficiency virus: A one-year longitudinal study. Journal of AIDS and Clinical Research, S9, 2. doi:10.4172/2155-6113.S9-002

Gibney, M., \& Vorster, H. (2001). South African food-based dietary guidelines. South African Journal of Clinical Nutrition, 14(3), S2.

Glanz, K., Burke, L. E., \& Rimer, B. K. (2011). Health behaviour theories. In J. B. Butts \& K. L. Rich (Eds.), Philosophies and theories for advanced nursing practice (pp. 247-269). Sudbury, MA: Jones and Bartlett Publishers.

Jaggers, J. R., Sneed, J. M., Lobelo, R. F., Hand, G. A., Dudgeon, W. D., Prasad, V. K., \& Blair, S. N. (2016). Results of a nine month home-based physical activity intervention for people living with HIV. International Journal of Clinical Trials, 3 (3), 106-119.

Lewis, B. A., Williams, D. M., Frayeh, A., \& Marcus, B. H. (2016). Self-efficacy versus perceived enjoyment as predictors of physical activity behaviour. Psychology and Health, $31(4), 456-469$.

Mabweazara, S. Z., Leach, L. L., \& Ley, C. (2017). Development of a context-sensitive physical activity intervention for persons living with HIVAIDS of low socioeconomic status using the Behaviour Change Wheel. Unpublished manuscript.

MacArthur, R. D., Levine, S. D., \& Birk, T. J. (1993). Supervised exercise training improves cardiopulmonary fitness in HIV-infected persons. Medicine and Science in Sports and Exercise, 25(6), 684-688. doi:10.1249/00005768-199306000-00006

Marcus, B. H., \& Simkin, L. R. (1993). The stages of exercise behaviour. The Journal of Sports Medicine and Physical Fitness, 33(1), 83-88.

Murenzi, A. (2011). Physical activity levels among people living with HIV/AIDS treated with high active antiretroviral therapy in Rwanda (Master's thesis). Retrieved from http://etd.uwc.ac.za/xmlui/handle/11394/1563

Neidig, J. L., Smith, B. A., \& Brashers, D. E. (2003). Aerobic exercise training for depressive symptom management in adults living with HIV infection. Journal of the Association of Nurses in AIDS Care, 14(2), 30-40.

O'Brien, K., Nixon, S., Glazier, R., \& Tynan, A. M. (2004). Progressive resistive exercise interventions for adults living with HIV/AIDS. Cochrane Database of Systematic Reviews, 4, CDo04248. doi:10.1002/14651858.CDo04248.pub2 
Prochaska, J. O., \& DiClemente, C. C. (1983). Stages and processes of self-change in smoking: Towards an integrative model of change. Journal of Consulting and Clinical Psychology, $51,390-395$.

Schwarzer, R., \& Renner, B. (2008). Health-specific self-efficacy scales. Retrieved from http://userpage.fu-berlin.de/ health/ healself.pdf

Smit, E., Crespo, C. J., Semba, R. D., Jaworowicz, D., Vlahov, D., Ricketts, E. P., ... Tang, A. M. (2006). Physical activity in a cohort of HIV-positive and HIV-negative injection drug users. AIDS Care, 18(8), 1040-1045.

Sparling, P. B., Owen, N., Lambert, E. V., \& Haskell, W. L. (2000). Promoting physical activity: The new imperative for public health. Health Education Research, 15(3), 367376.

Spence, D. W., Galantino, M. L., Mossberg, K. A., \& Zimmerman, S. O. (1990). Progressive resistance exercise: Effect on muscle function and anthropometry of a select AIDS population. Archives of Physical Medicine and Rehabilitation, 71(9), 644-648.

Stacey, F. G., James, E. L., Chapman, K., Courneya, K. S., \& Lubans, D. R. (2015). A systematic review and meta-analysis of social cognitive theory-based physical activity and/or nutrition behaviour change interventions for cancer survivors. Journal of Cancer Survivorship, 9(2), 305-338.

Titheridge, H., Christie, N., Mackett, R., Oviedo Hernandez, D., \& Ye, R. (2014). Transport and poverty. A review of the evidence. London: UCL.

Tuso, P. (2015). Strategies to increase physical activity. The Permanente Journal, 19(4), 84-88.

Webel, A. R., Moore, S. M., Hanson, J. E., \& Salata, R. A. (2013). The rationale, design, and initial efficacy of SystemCHANGE ${ }^{\mathrm{TM}}$-HIV: A systems-based intervention to improve physical activity in people living with HIV. Journal of AIDS and Clinical Research, 4(3). doi:10.4172/ 2155-6113.1000200

World Health Organization. (2006). Global physical activity questionnaire (GPAQ). Geneva: Author. 